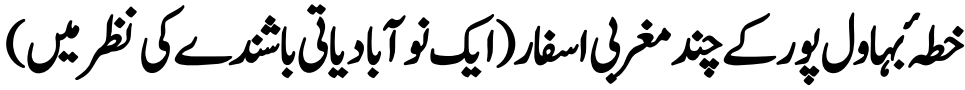

\section{A Few Western Trips to the Bahawalpur Region (In the Eyes of a Colonialist)}

Saira Irshad

Lecturer, Department of Urdu, Government Sadiq College Women University Bahawalpur, Pakistan

\section{K E Y W O R D S}

\section{Western}

Colonial Powers

Travel

Civilization and Culture

Nonnative

D A T E S

\begin{tabular}{ll}
\hline Received & $14-07-2021$ \\
Accepted & $03-09-2021$ \\
Published & $19-09-2021$
\end{tabular}

QR CODE

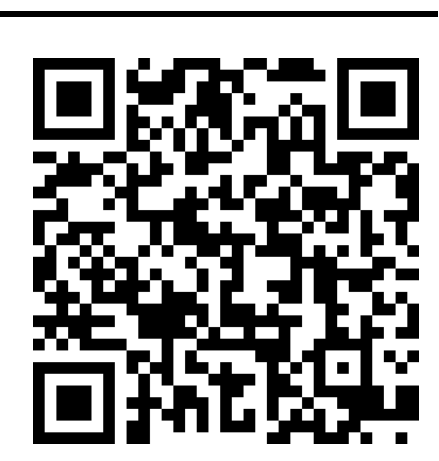

\section{A B S T RA C T}

Where the western colonial powers have had a profound influence on other forms of literature, such a genre of travel journalism in the Bahawalpur region could not be safeguarded. The region is known for its civilization and culture, yet the rumors that have been written from Pakistan to Pakistan remain mournful that the tradition under the influence has stirred. Although the nature of the journals being written in the Bahawalpur region varied, the correspondents here discussed the impact that the west had given them. At the national level, the ambassadors sought for western couples and also showed an attitude of disregarding civilization and culture. At the national level, the ambassadors sought for western couples and also showed an attitude of disregarding civilization and culture. Travelling entrepreneurs separate from their country apart from a new angle and independent thinking, they seem to be lacking in the west. This difference can be seen even more clearly if domestic and international travels are taken into account.

DOI: https://doi.org/10.54064/negotiations.v1i2.13

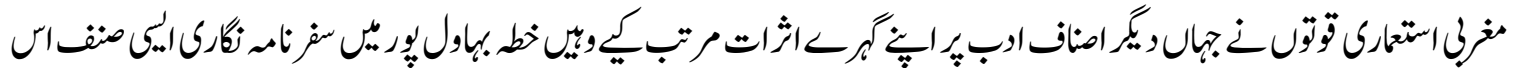

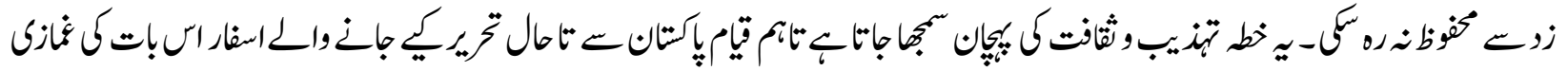

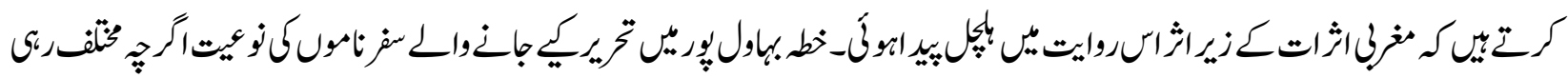

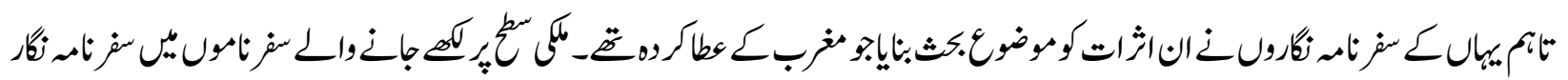

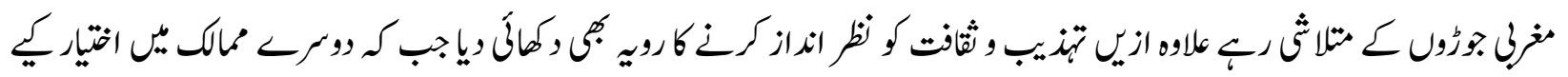






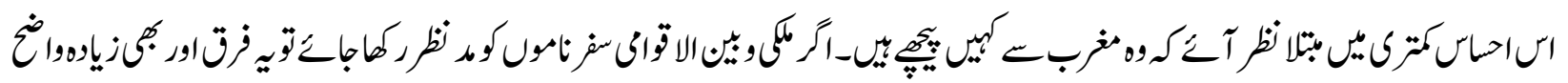

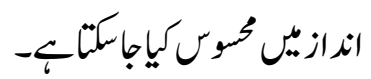

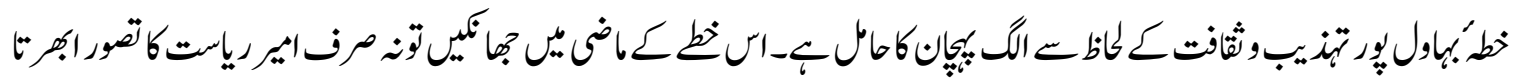

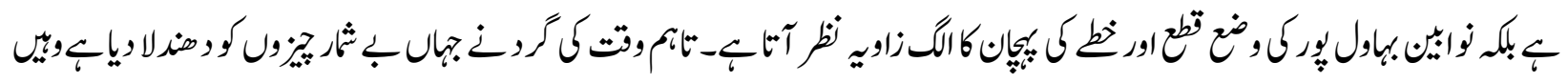

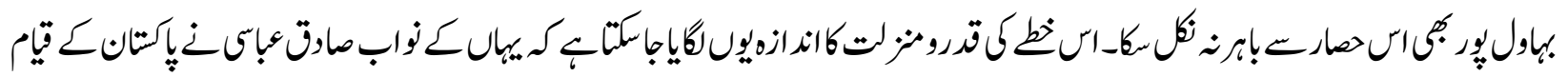

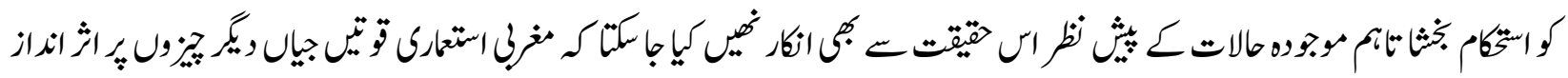



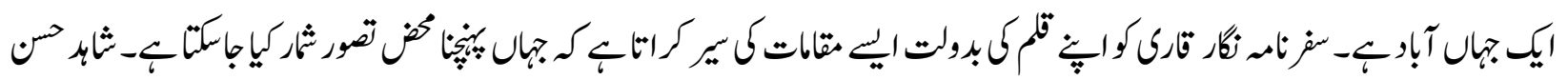



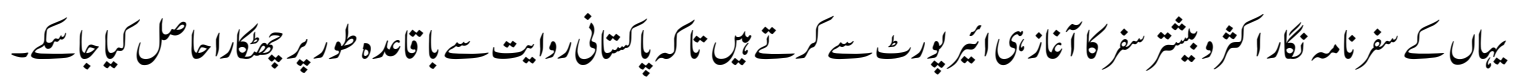

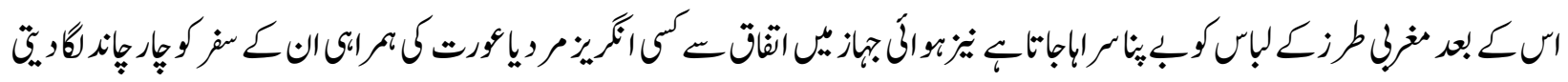

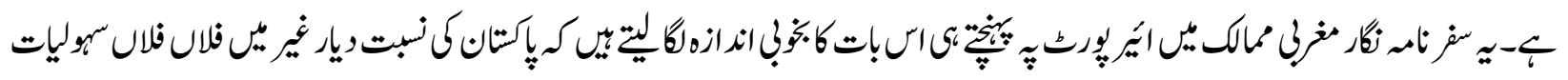



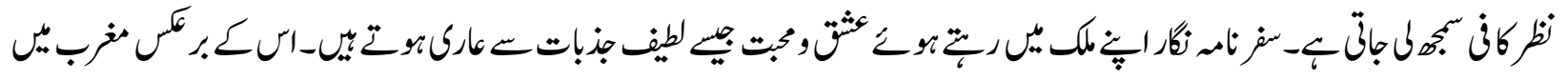

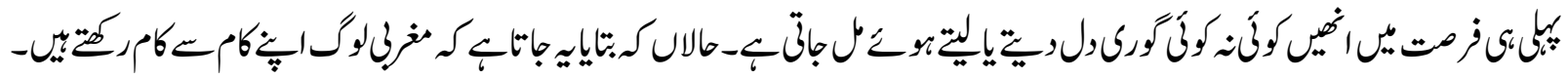



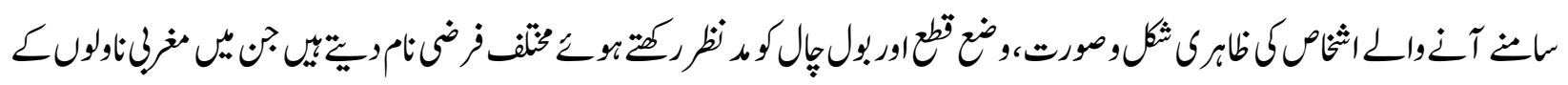

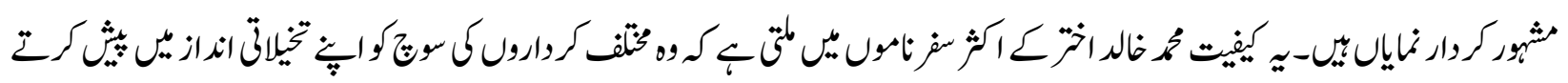

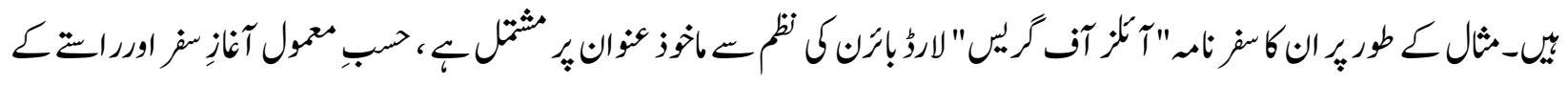

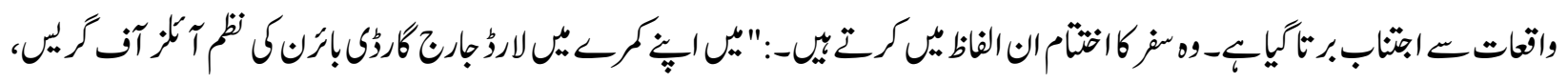

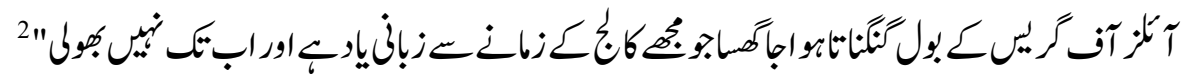

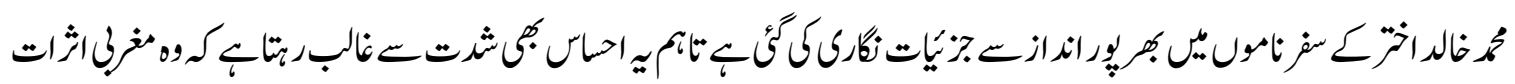

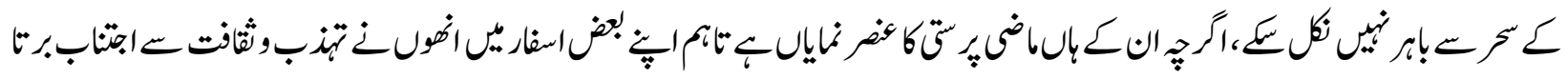

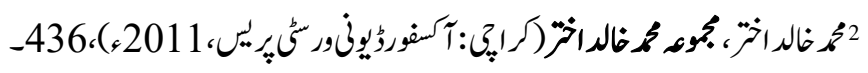




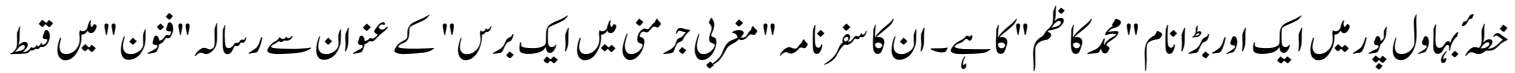

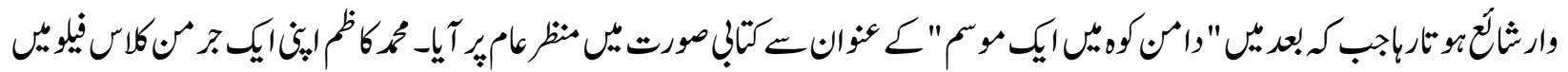

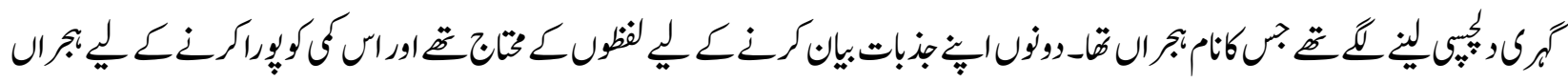

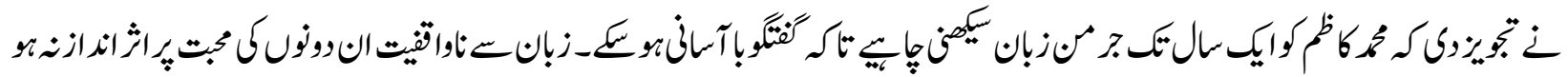

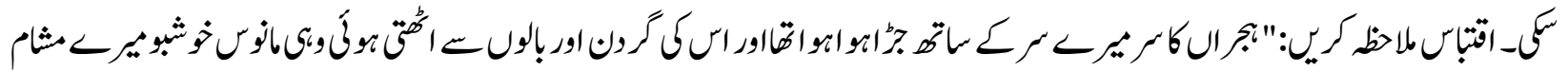

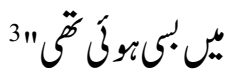

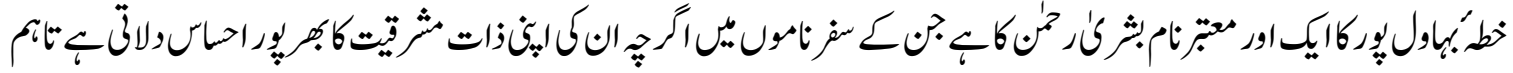

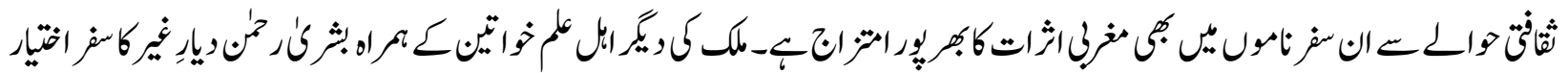

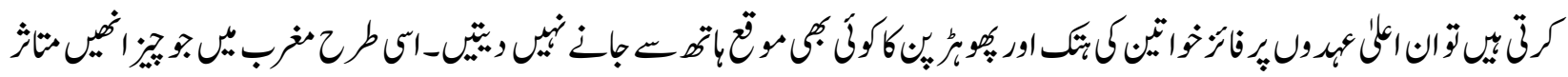

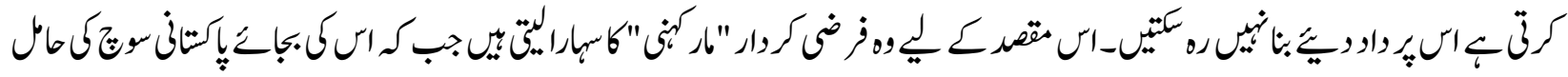

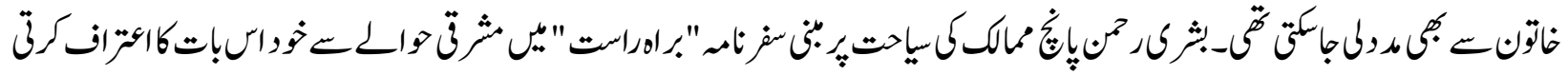

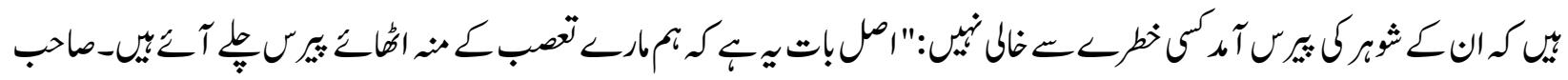

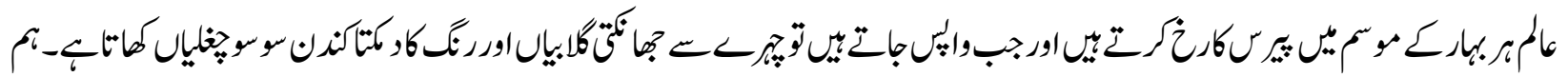

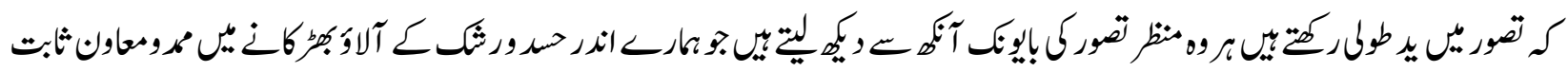

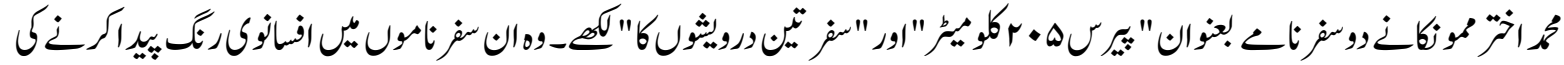

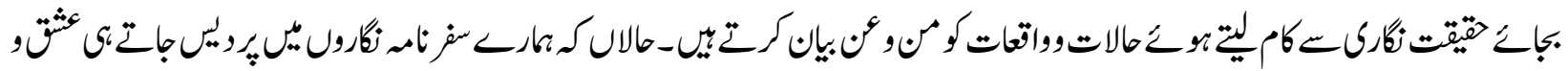

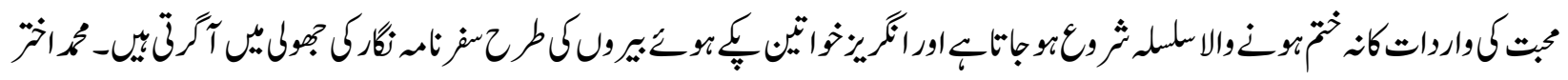



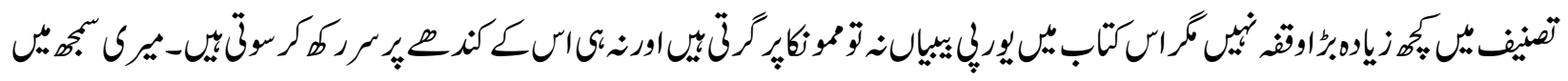

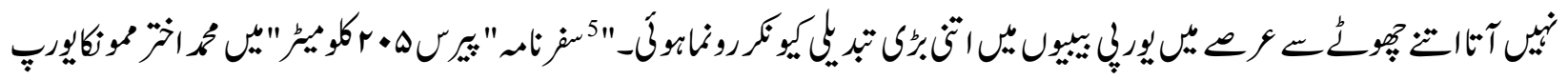



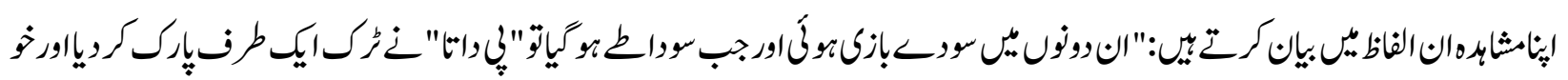



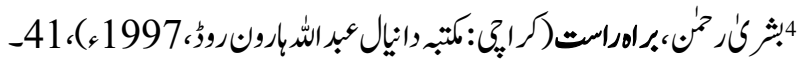

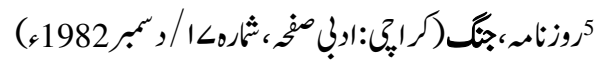






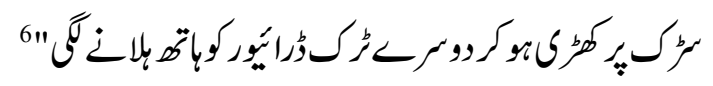

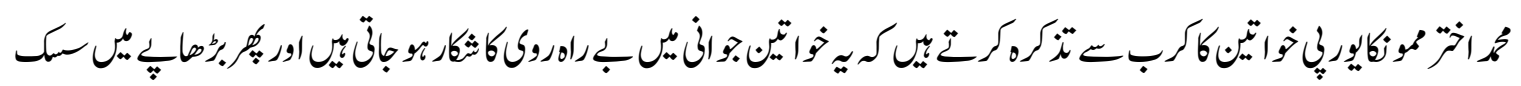

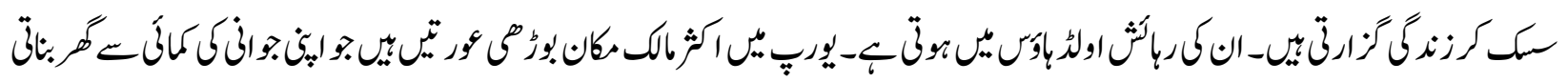

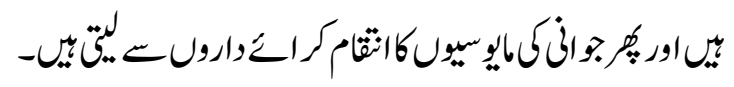

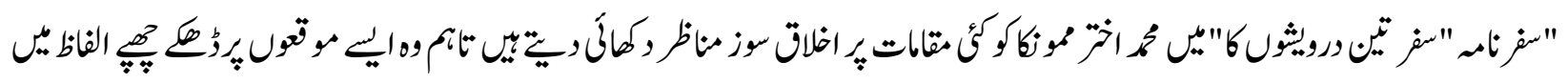

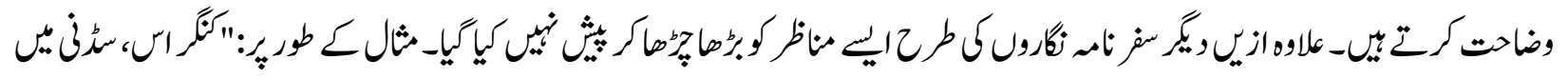

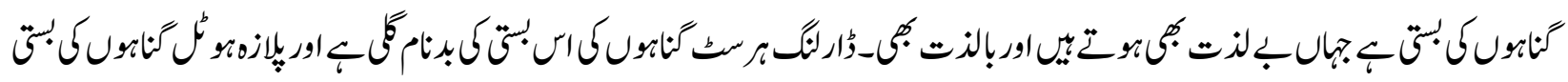



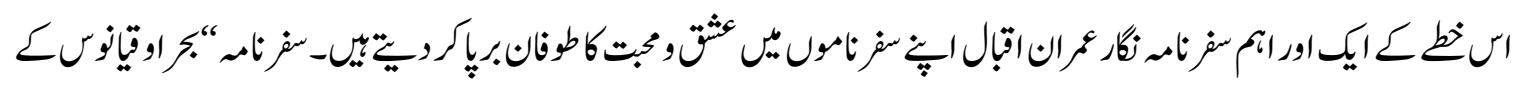



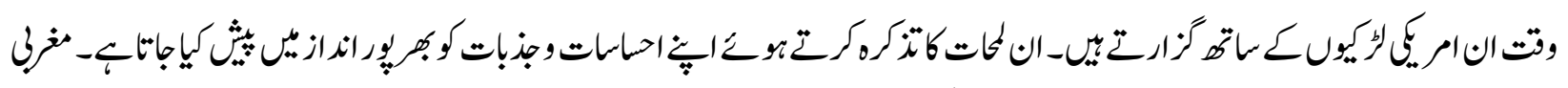

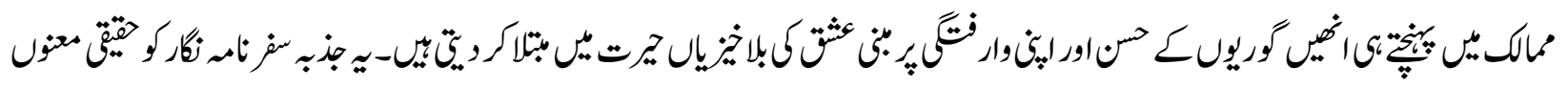



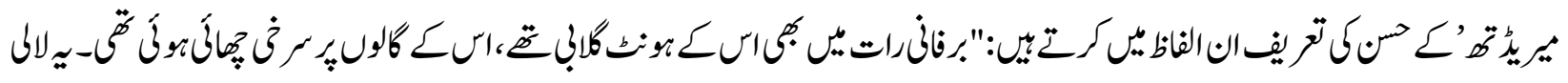

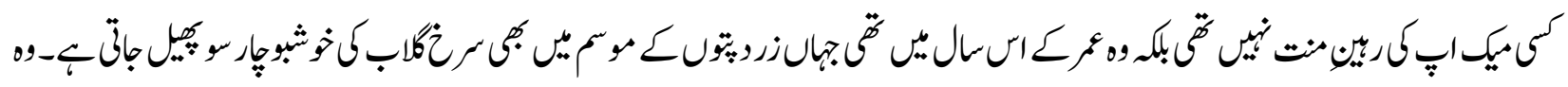

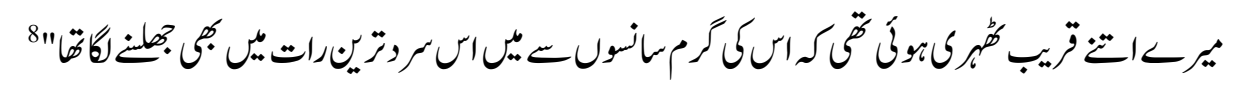

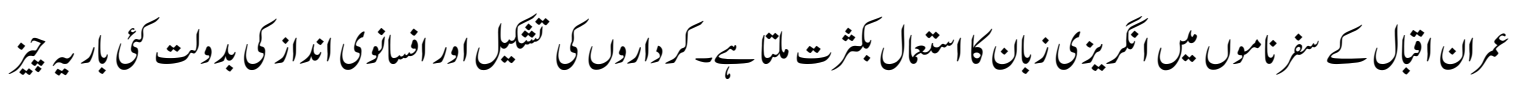



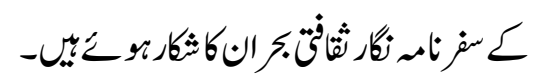

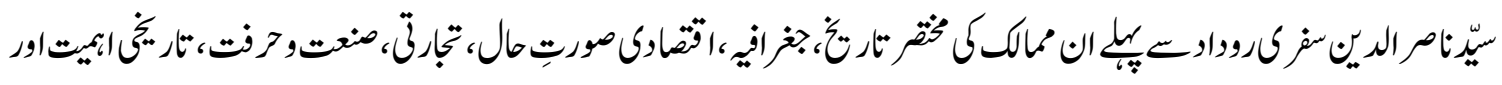

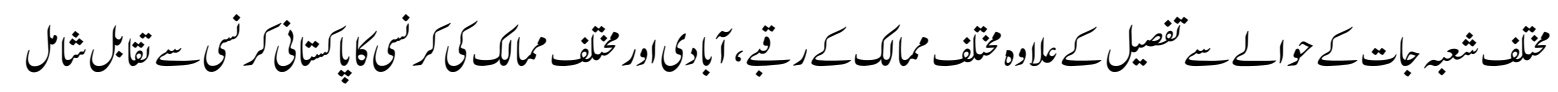



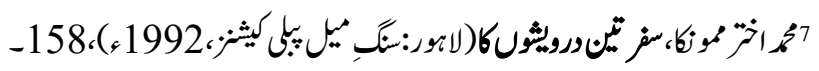

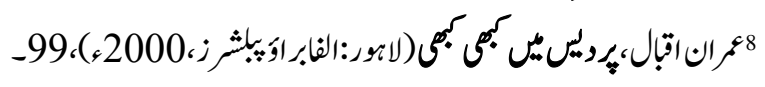




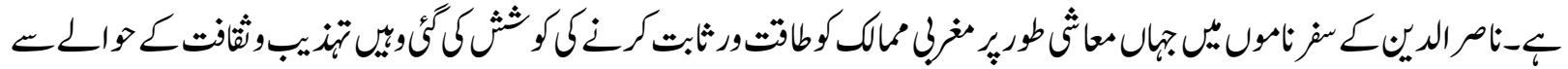

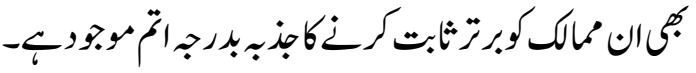



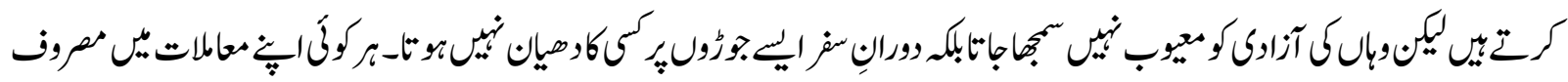



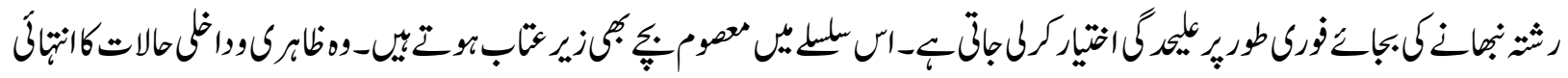

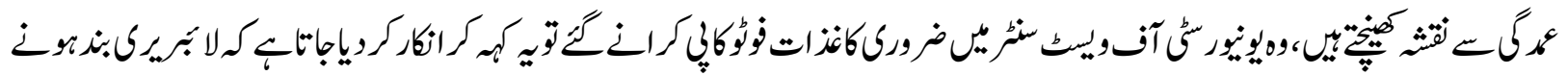

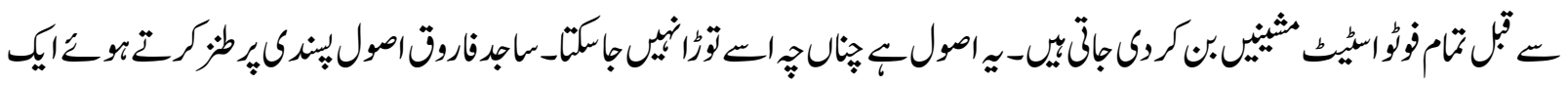
واقدبيان كرت تيك:

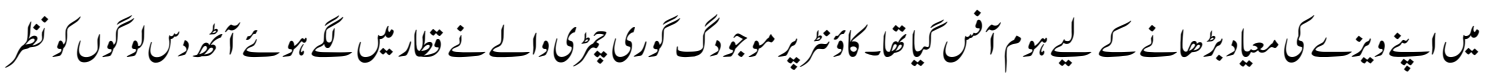



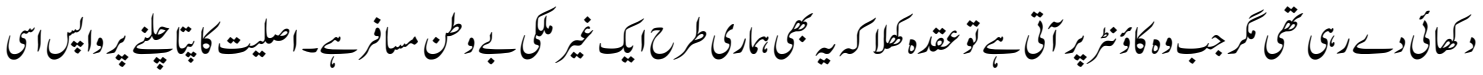

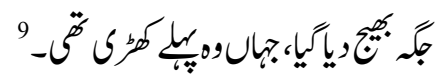

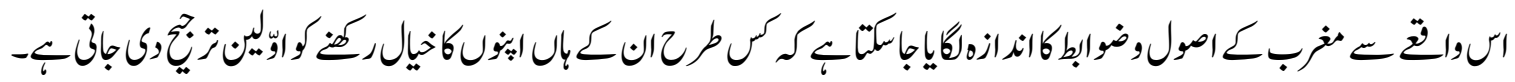

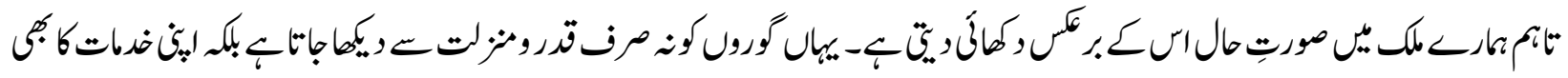

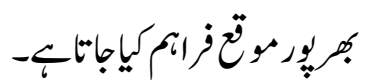

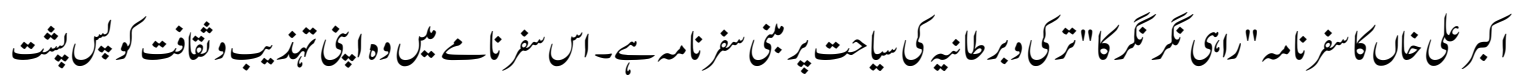

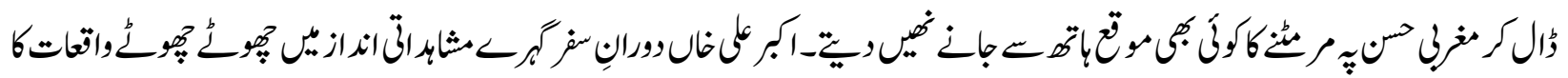

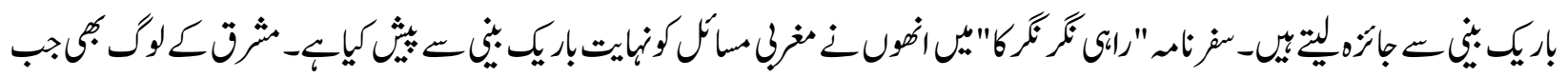

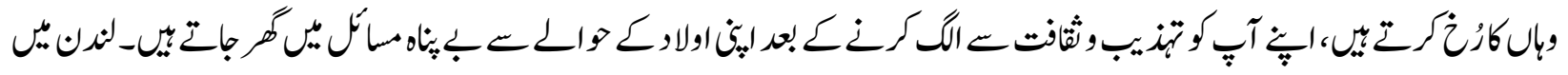

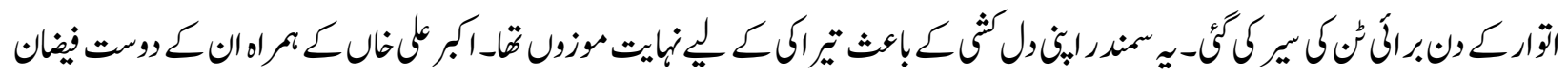

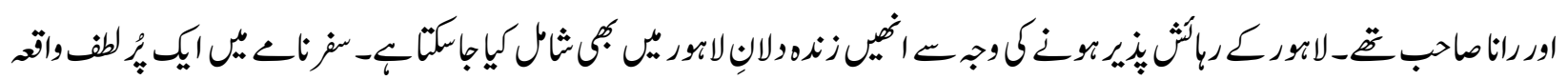

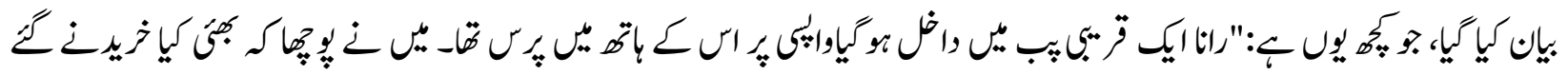

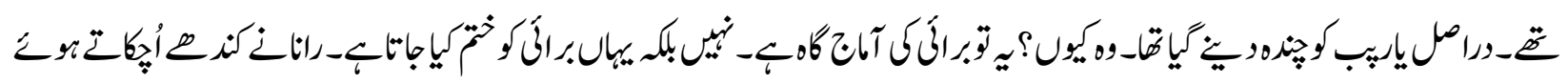

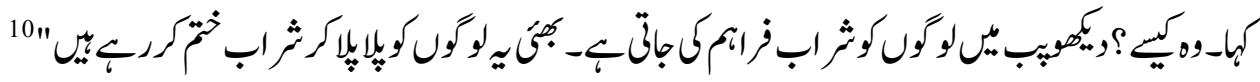

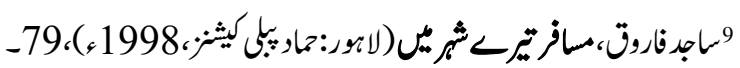

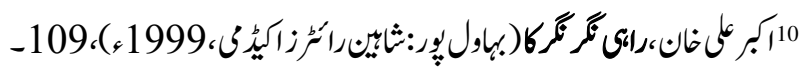




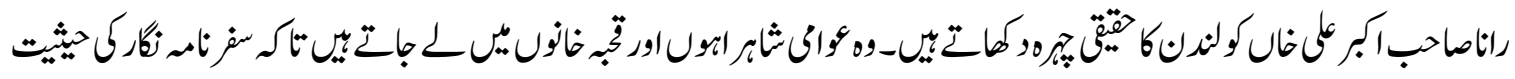

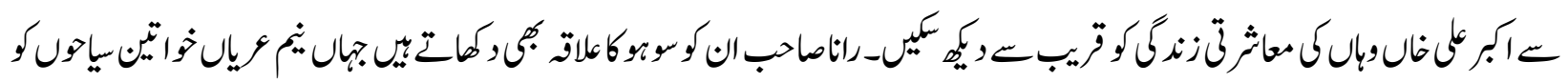

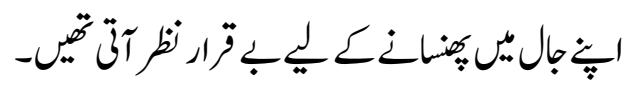

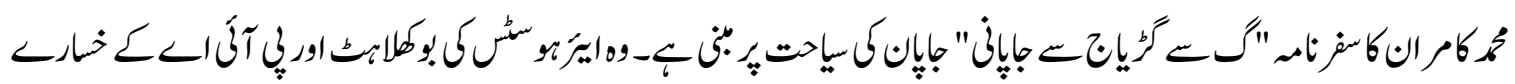

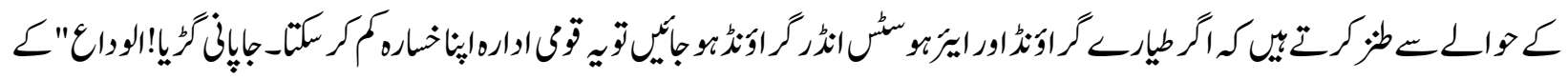

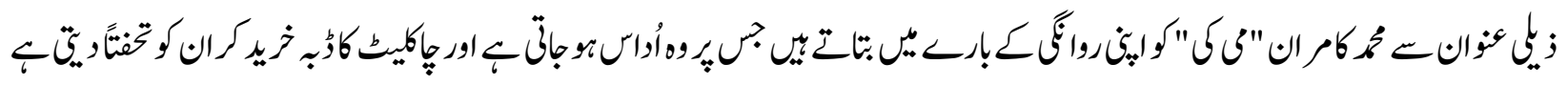

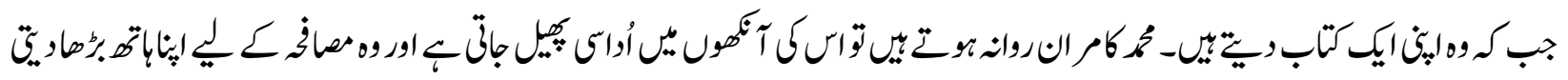

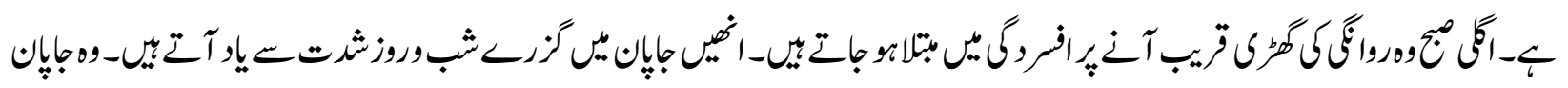

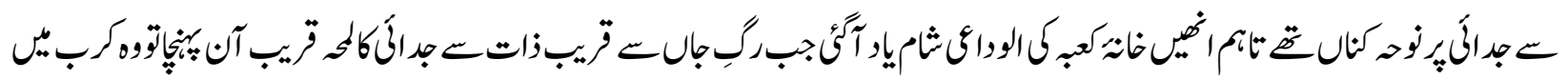

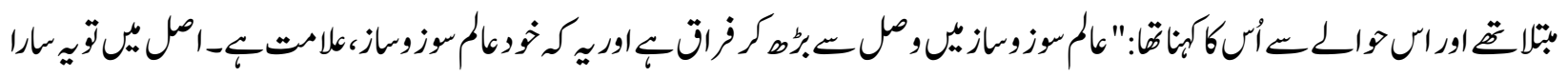
$111 " 60$

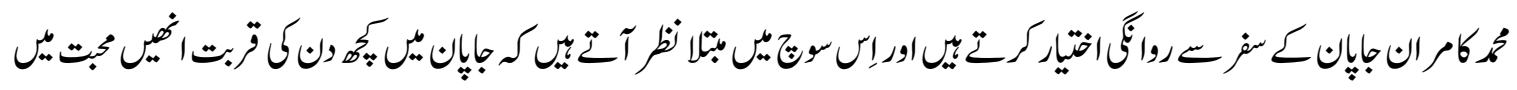

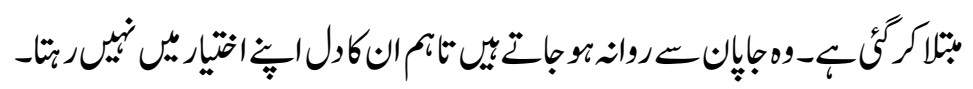

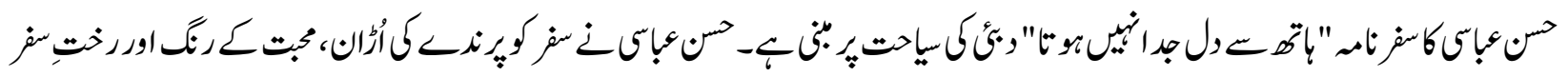

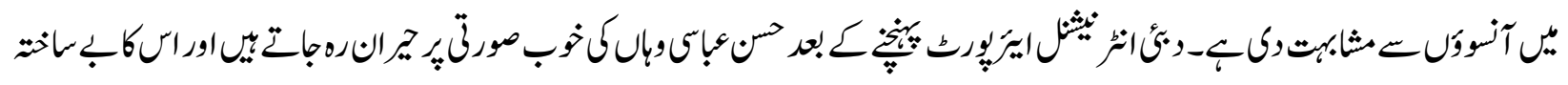

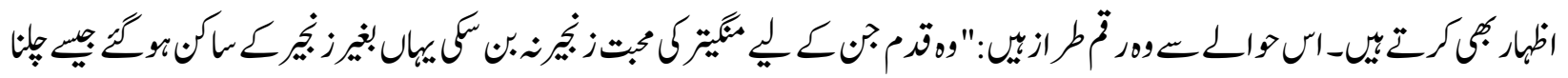

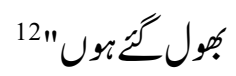

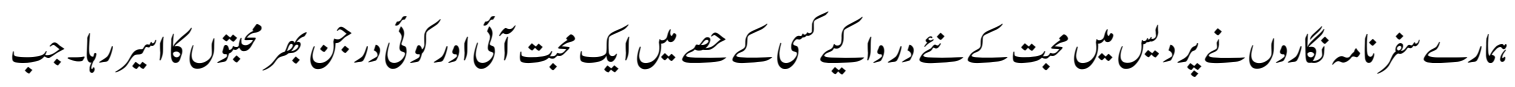

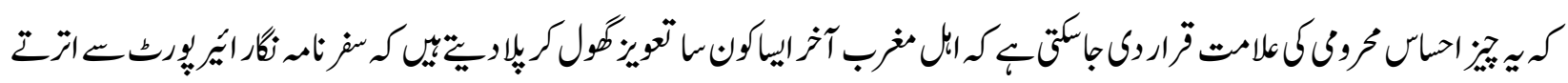

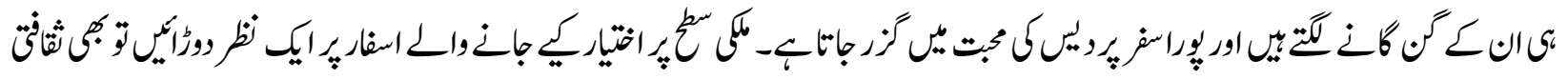

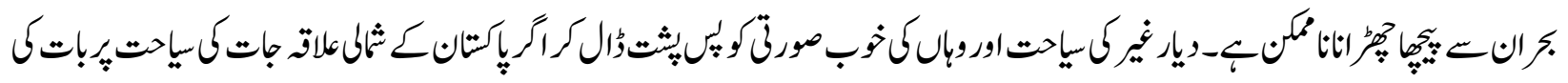

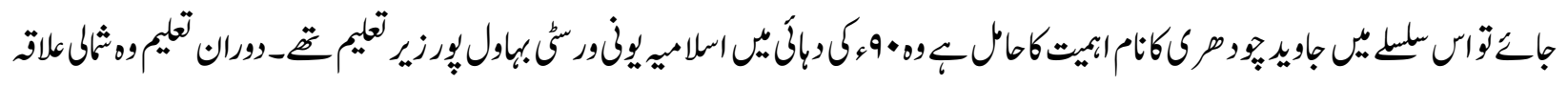

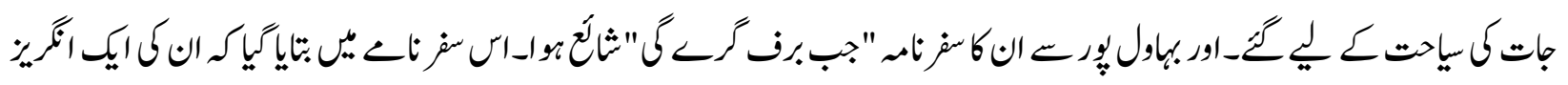

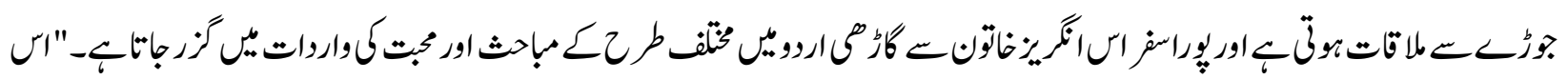

${ }^{1}$ http://Urdunetijpn.com/ur/2009/11/20/dr_kamran_ka_Safarnama_Japan. EPI:13, Page.113

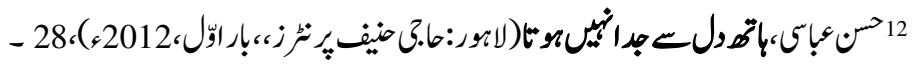




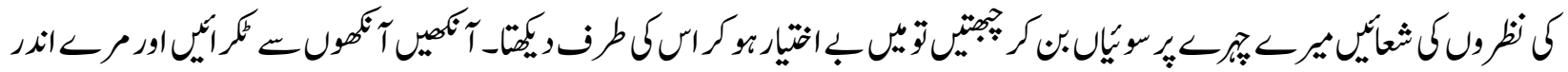

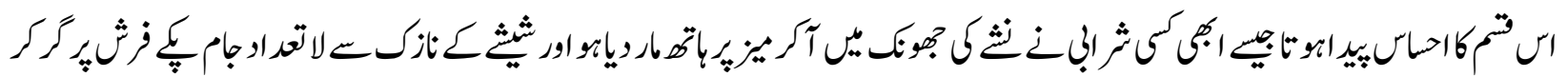

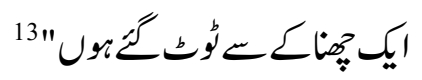

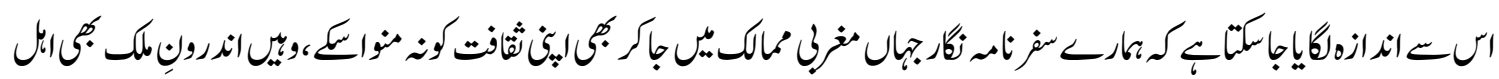

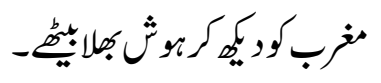



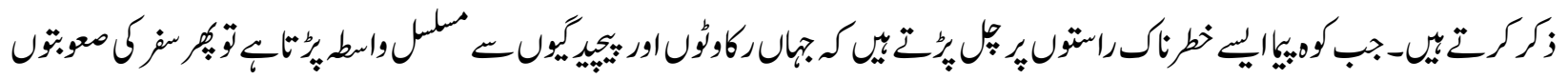

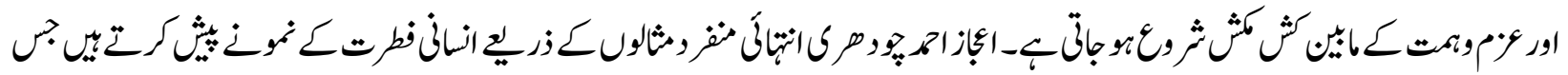

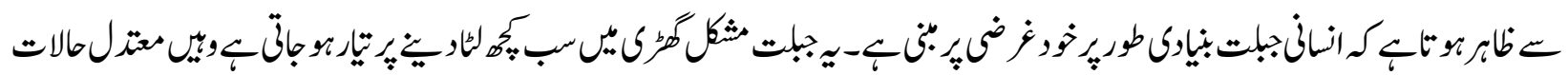

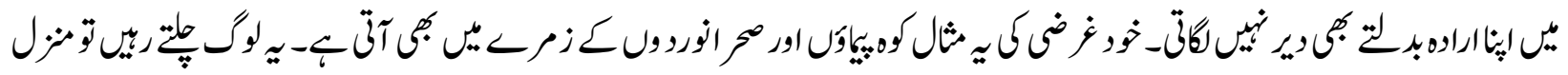



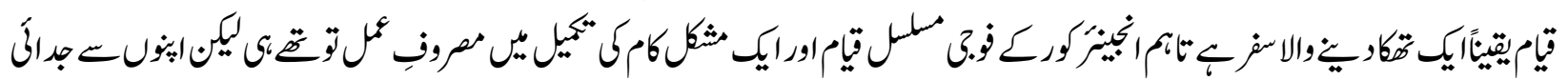





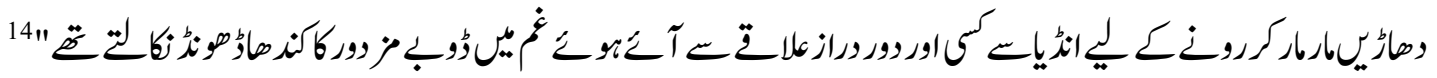

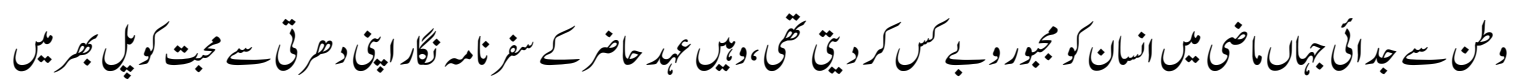

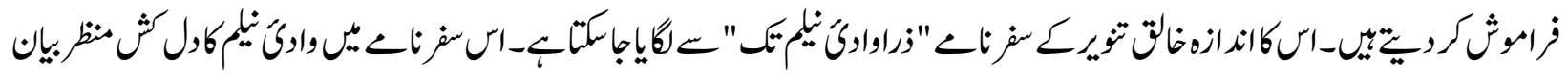



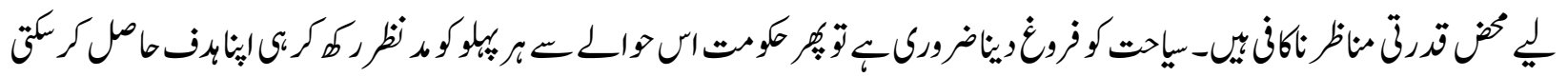

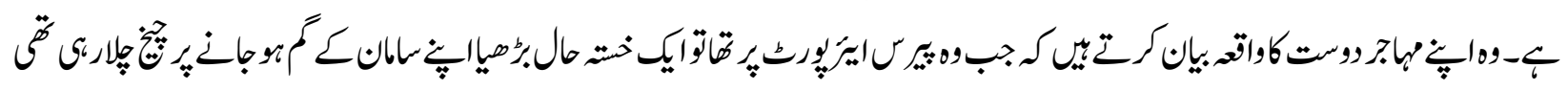

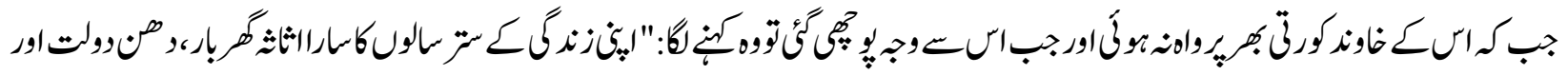

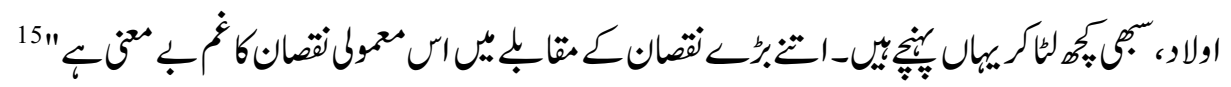

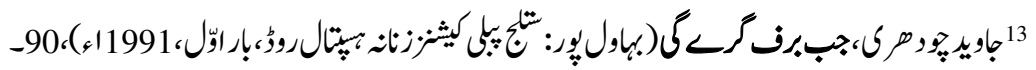

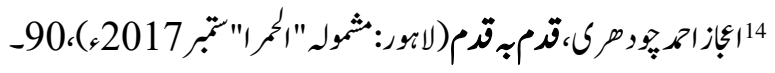

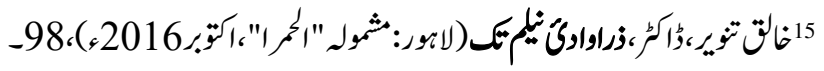




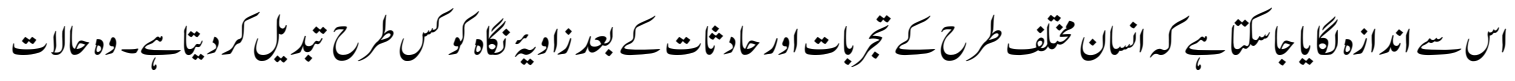



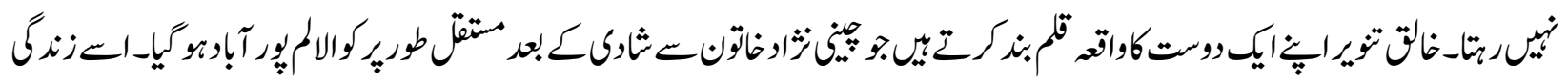

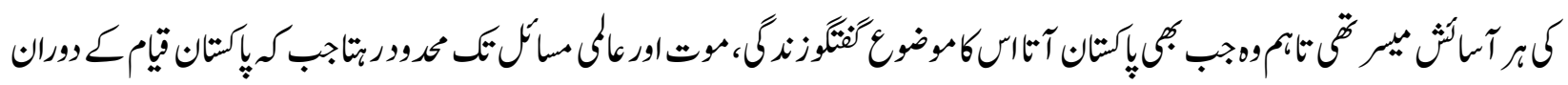

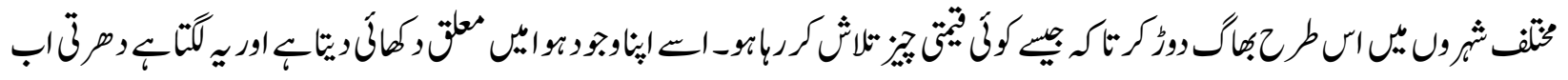



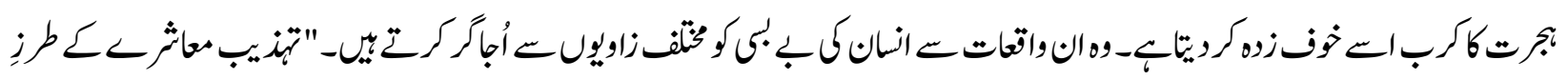





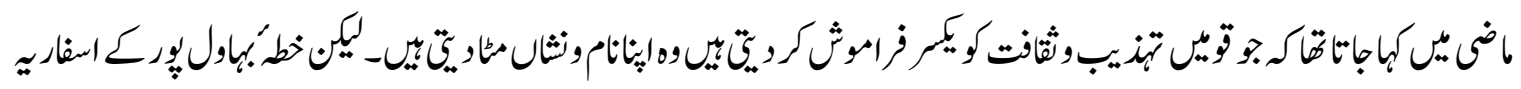



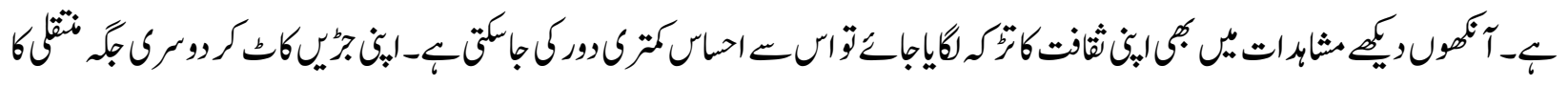



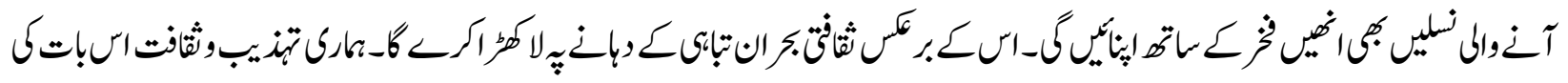

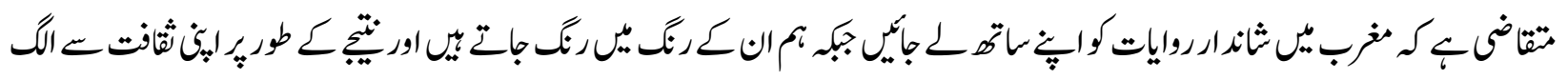

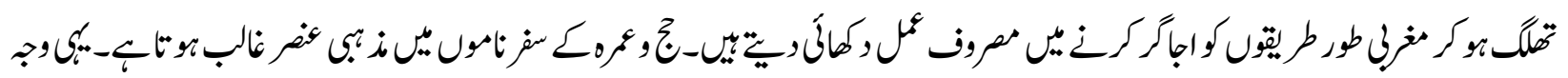

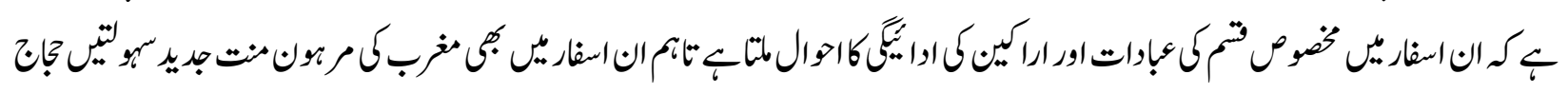



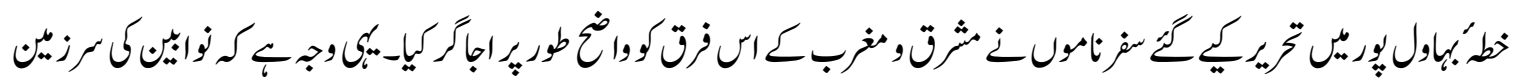

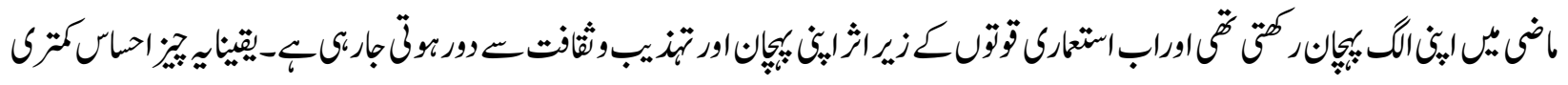

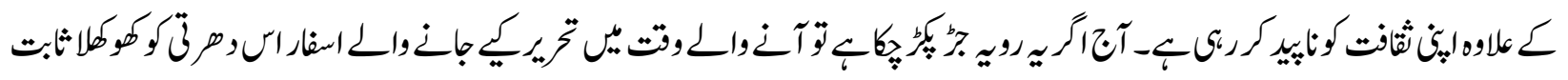

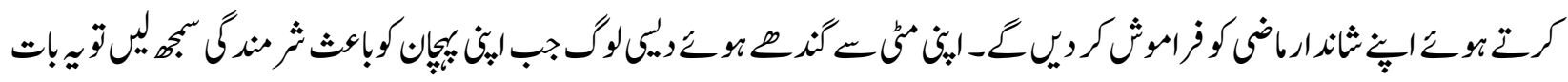

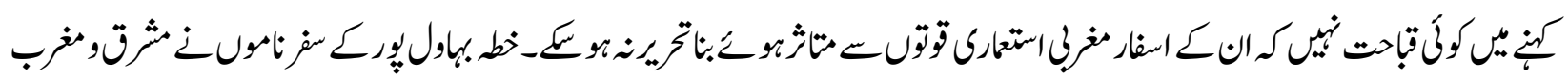

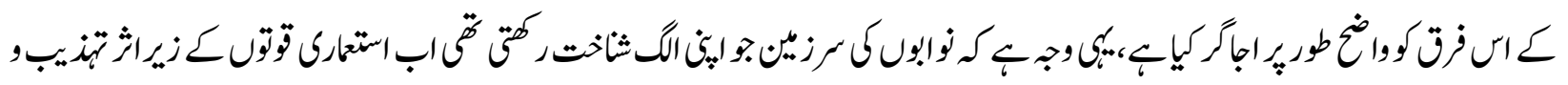




$$
\begin{aligned}
& \text { ثثافت }
\end{aligned}
$$



论论㶦 